\title{
A ERA RELIGIOSA-POLÍTICA DE BOLSONARO E OS PENTECOSTAIS NO BRASIL
}

\author{
The Religious-Political Age of Bolsonaro and Pentecostals in Brazil \\ Una Era Religiosa-Política de Bolsonaro e los pentecostales no Brasil
}

\begin{abstract}
Received: april/2020
Acceped : june/2020

Available: june/2020
\end{abstract}

Jimmy Barbosa Pessoa, Mestrando em Ciência da Religião, Pontifícia Universidade Católica de

São Paulo - PUC-SP, Brasil. E-mail: jimmybpessoa@gmail.com

\begin{abstract}
Resumo: O presente trabalho é uma reflexão com análises sociológica e da Ciência da Religião sobre a perspectiva do voto evangélico-pentecostal e a campanha do presidente eleito em 2018, Jair Messias Bolsonaro. Que através de um discurso militarizado, com apelo religioso, falas e práticas populistas e centrado em um lema: "Brasil acima de tudo e Deus acima de todos", conseguiu o apoio de grande parte do público pentecostal para serem seu eleitorado. Este artigo foi elaborado a partir do método de pesquisa bibliográfica, tendo sido realizado a busca por informações em sites, artigos e textos. E por meio dessa técnica metodológica, elaboramos uma discussão que tratou de produzir análises tanto do período eleitoral como de fatos que foram preponderantes para o fortalecimento do nome de Bolsonaro para presidente do Brasil entre os grupos pentecostais antes do ano de 2018, e no decorrer da consolidação de sua candidatura. Havendo ainda, uma apresentação da participação político-religiosa dos pentecostais no cenário político brasileiro com uma breve apresentação histórica. Também foi considerado alguns pontos do resultado eleitoral deste pleito que entendemos ter sido determinantes em todo período pré-eleitoral como na disputa nos dias de campanha. Nosso objetivo primordial neste artigo, é apresentar um novo olhar sobre a necessidade de considerável atenção e dedicada análise do apoio do movimento pentecostal brasileiro como um fenômeno que se destaca em toda campanha do presidente eleito.
\end{abstract}

Palavras-Chaves: Pentecostalismo, Religião, Bolsonaro, Política.

Abstract: The present work is a reflection with sociological and Science of Religion analyzes on the perspective of the evangelical-Pentecostal vote and the campaign of the president-elect in 2018, Jair Messias Bolsonaro. That through

RBPPD/BRJPD | Vol. 2 | n. 2 | p. 109-127, 2020. 
a militarized discourse, with religious appeal, populist speeches and practices and centered on a motto: "Brazil above all and God above all", he obtained the support of a large part of the Pentecostal public to be his electorate. This article was prepared based on the bibliographic search method, and the search for information on websites, articles and texts was carried out. And through this methodological technique, we elaborated a discussion that tried to produce analyzes both of the electoral period and of facts that were preponderant for the strengthening of the name of Bolsonaro for president of Brazil among the Pentecostal groups before the year 2018, and during the consolidation of your candidacy. There is also a presentation of the political-religious participation of Pentecostals in the Brazilian political scene with a brief historical presentation. Some points of the electoral result of this election were also considered, which we believe to have been decisive throughout the pre-electoral period, such as in the dispute on campaign days. Our primary objective in this article is to present a new look at the need for considerable attention and dedicated analysis of the support of the Brazilian Pentecostal movement as a phenomenon that stands out in every campaign of the president.

Keywords: Pentecostalism, Religion, Bolsonaro, Politics.

Resumen: El presente trabajo es una reflexión con análisis sociológicos y de Ciencia de la Religión sobre la perspectiva del voto evangélico-pentecostal y la campaña del presidente electo en 2018, Jair Messias Bolsonaro. Que a través de un discurso militarizado, con atractivo religioso, discursos y prácticas populistas y centrado en un lema: "Brasil sobre todo y Dios sobre todo", obtuvo el apoyo de una gran parte del público pentecostal para ser su electorado. Este artículo se elaboró a partir del método de investigación bibliográfica, habiéndose realizado la búsqueda de información en sitios web, artículos y textos. Y a través de esta técnica metodológica, elaboramos una discusión que trató de producir análisis tanto del período electoral como de los hechos que fueron preponderantes para el fortalecimiento del nombre de Bolsonaro para presidente de Brasil entre los grupos pentecostales antes del año 2018 y durante el Consolidación de su candidatura. También hay una presentación de la participación político-religiosa de los pentecostales en la escena política brasileña con una breve presentación histórica. También se consideraron algunos puntos del resultado electoral de esta elección, que creemos que han sido decisivos durante todo el período preelectoral, como en la disputa en los días de campaña. Nuestro objetivo principal en este artículo es presentar una nueva mirada a la necesidad de una atención considerable y un análisis dedicado del apoyo del movimiento pentecostal brasileño como un fenómeno que se destaca en toda la campaña del presidente electo.

Palabras clave: Pentecostalismo, Religión, Bolsonaro, Política.

\section{Introdução}

O movimento de políticos conservadores é uma temática que tem aparecido no noticiário mundial constantemente nos últimos quatro anos. Seja a eleição do presidente Donald Trump nos Estados Unidos, de parlamentares nacionalista, de ultradireita ou de partidos neonazistas na Europa, e outros termos relacionados a ideologias arraigadas de populismo e conceitos tradicionais com base em moralismo, liberalismo e com traços conservadores nos costumes como se apresentam alguns postulantes ao poder no Brasil e fora dele. Essa temática além de ser instigante, curiosa e de crescentes pesquisas no mundo acadêmico e científico. É também de interesse de grande parte da população mundial, que ouvindo e assistindo esses temas pelos meios de comunicação, tem buscado mais informações sobre a política e pretensos candidatos.

E nessa onda conservadora, as terras tupiniquins também tiveram seus dados históricos a serem registrados e analisados. Sendo apontado como parte desta onda conservadora, um fenômeno 
que merece atenção e dedicado estudo, é a eleição em 2018, de Jair Bolsonaro a presidência do Brasil e a contribuição do movimento pentecostal nessa escolha eleitoral, que apresentou um resultado diferente das ultimas seis eleições ocorridas para presidente, onde nenhum candidato de direita ou extrema-direita, chegou se quer a disputa de segundo turno. E nesse pleito, não apenas chegou ao segundo turno, como foi eleito com uma margem significativa de votos.

A temática da era-religiosa política de Bolsonaro e os pentecostais no Brasil, foi elaborada e escolhida, por ser entendido que este tema deve ser campo de pesquisa e análises das ciências humanas, devido a importância de se buscar entender questões relacionadas ao campo político e religioso em um período pós-moderno. Momento este que apontava para às ideias progressistas em tese geral, tendo essa perspectiva, grande entrada na sociedade brasileira, porém o resultado de uma eleição no executivo e no legislativo, e os fatos já acontecido no pleito municipal de 2016, revelaram que uma guinada conservadora que fez o país caminhar para outro sentido.

Estudar essa temática, é antes perceber o campo em que se está pisando. Sendo necessário primeiro, compreender a história dos pentecostais no Brasil e a participação política desse grupo religioso; em segundo lugar, saber como os parlamentares, lideres pentecostais e integrantes dessas instituições, construíram seu relacionamento com Bolsonaro e por último, analisar fatos importantes que potencializaram as possibilidades para a eleição de uma projeto político que era antagônico aos últimos três presidentes eleitos no Brasil. Nestas percepções se apresenta a importância deste trabalho, que busca compreender e analisar a partir de uma posição onde se contemple a influência do movimento das forças religiosas pentecostais no campo da disputa eleitoral nos poderes executivo e legislativo brasileiro.

Os pentecostais aportaram no Brasil em 1910, sendo fundado por missionários estrangeiros no Norte e no Sul brasileiro. No Sul, em 1910, é fundada a Congregação Cristã do Brasil (CCB), na cidade de São Paulo, por imigrantes italianos. No norte do Brasil, em Belém do Pará, em 1911, surge a Assembleia de Deus. Fruto do trabalho de dois missionários suecos, que em poucas décadas se espalha pelo país, e torna-se a maior denominação evangélica do Brasil, e ainda sendo troco de outras inúmeras igrejas pentecostais (ARAUJO, 2007; ALENCAR, 2013).

Ambas às denominações, tem características conservadoras, firme nos costumes e liturgia rígida. Dirigidas por pastores com pouca formação escolar por muitas décadas, esses ministros religiosos se destacavam por falarem a língua do povo, estavam nas periferias, povoados e nos

RBPPD/BRJPD | Vol. 2 | n. 2 | 109-127, 2020. 
longínquos vilarejos. Estabelecendo assim uma relação de apoio e atuação junto a comunidade, sendo os mesmos mais forte que o estado em atuação social. Tornando-se a igreja como o referencial de vida social e comunitária para milhões de pessoas desamparadas pelo poder publico.

O motivo da produção deste artigo, é a percepção da importância de compreender quais fatores sociológicos e políticos, levaram os pentecostais em sua maioria, apoiar Jair Messias Bolsonaro para presidente do Brasil no pleito de 2018. Quais foram os motivos dessa decisão que mais influenciaram? Que fatos pré-eleitorais foram decisivos para essa guinada mais conservadora e qual a mensagem e ações aproximaram Bolsonaro dos pentecostais e os pentecostais de Bolsonaro?

Ainda sendo inquietado pelos motivos trazidos por membros com os quais foi conversado sobre suas percepções sobre a eleição para presidente, indagando-os em que candidatos votariam e analisando suas respostas e motivos da escolha de Bolsonaro. Ao registrar os motivos que eram: os discursos antipolítica, valorização do seu lema de campanha: "Brasil acima de tudo e Deus acima de todos"; a facilidade na liberação do uso de armas por cidadãos de bem; sua esposa ser evangélica; ser contra "a ideologia de gênero", ser contra o aborto, etc.

O objetivo geral desse artigo é investigar, registrar e analisar os principais motivos da relação do voto e apoio de pentecostais ao candidato eleito Jair Messias Bolsonaro para presidente da República do Brasil na eleição de 2018.

Tivemos como objetivos específicos nesse artigo:

1 - Trazer um panorama da origem da relação pentecostal e neopentecostal na política brasileira; 2 - Fazer uma breve exposição da situação política do Brasil antes da eleição de 2018;

3 - Apresentar a relação entre os pentecostais no parlamento e líderes das igrejas evangélicas com Jair Bolsonaro;

4 - Realizar uma breve apresentação da campanha de Bolsonaro e articulação do seu nome no processo eleitoral por meio de seu lema de campanha e propostas, buscando apresentar alguns pontos dos resultados dessa relação e o processo eleitoral que levou Bolsonaro a presidência do Brasil.

A metodologia usada para colher os dados analisados nesse artigo, seguiu o método de pesquisa bibliográfica, através de textos que tratam sobre o movimento pentecostal e sua participação política, informações sobre fatos políticos e referencias teóricos sobre política e

RBPPD/BRJPD | Vol. 2 | n. 2 | 109-127, 2020. 
religião. Segundo Severino (2015, p. 122) “A pesquisa bibliográfica é aquela que se realiza a partir do registro disponível, decorrente de pesquisa anteriores, em documentos impressos, como livros, artigos, teses, etc. Utiliza-se de dados ou de categorias teóricas já trabalhados por outros pesquisadores e devidamente registrados".

Este artigo foi elaborado a partir da perspectiva de apresentar informações sobre a perspectiva política a partir do registro e divulgação de dados que tratam sobre o pentecostalismo por meio de registro históricos e análises dos dados a partir de uma lente da Ciência da Religião, Sociologia e reflexões que apontem novas possibilidades de compreensão do fenômeno pentecostal e sua relação com o poder político no estado brasileiro. Conhecendo a história desse movimento, seus interesses no campo político, suas nuances no enfrentamento eleitoral no contexto políticoreligioso e seus atuais movimentos na construção de alianças com políticos com discursos conservadores como Bolsonaro, que superando todos os analistas e políticos de alto escalão em suas primeiras análisesı, venceu a eleição para presidente do Brasil com forte apoio evangélico, católico e pentecostal.

\section{Tratando sobre a relação entre religião e política no Brasil}

A construção política brasileira é repleta de curiosidades, novidades e inimagináveis resultados até para os mais experientes e preparados quando o assunto é eleição. Desde a instalação da República no Brasil no ano de 1889, organizada com grande participação militar, o percurso histórico da política brasileira atravessou da era Vargas, em seus dois momentos, nos governos de Dutra, Kubitschek, Jânio, Goulart, os presidentes militares e os presidentes pós a redemocratização. Um combinado de disputas e lutas pela direção nacional entre grupos, indivíduos, partidos e ideologias; que serviram como alicerces para desejos de mudança e continuísmo de lados opostos, mas ambos com os mesmos fins, o poder (COSTA e MELLO, 1999).

Em todos os momentos históricos e de situações inesperadas na jornada da Nova República, que se inicia com a redemocratização a partir de 1985. É percebido um combinado de fatos que estão correlacionados pela influência de grupos internos e fatos externos, que sempre influenciaram

1 Por meio de uma rápida pesquisa, poderá ser encontrado em vídeos e entrevistas, que ex-presidentes, candidatos, cientistas políticos e outros especialistas no tema de política, não apontavam e não acreditavam na eleição de Bolsonaro para presidente do Brasil em 2018.

RBPPD/BRJPD | Vol. 2 | n. 2 | 109-127, 2020. 
nos processos eleitorais e do governo brasileiro. Seja por meio de questões ideológicas, investimento financeiro, formas da fazer política, apoio popular e interesses de partidos e sujeitos políticos. Entre todo este percurso histórico, está presente o espectro religioso. Questão fundamental para maioria dos brasileiros e brasileiras que fazem esta nação. Por isso tem o dito popular: "Perco tudo, menos a fé em Deus, pois Deus tem muito mais para me dar, do que o diabo para me tirar"'(essa frase provavelmente foi escrita no Brasil, pois o diabo-homem tem roubado estas terras de todas às formas desde a chegada dos europeus, e ainda o país possui riquezas incontáveis).

A participação religiosa no processo político brasileiro, sempre foi tão presente como cédula, urna e escrutínio secreto em dia de eleição. Desde o que é chamado de colonização desta terra chamada Brasil, apresentada oficialmente em 1500, até os dias atuais. Religião e política não só caminharam juntas. Mas se apaixonaram, amaram-se, moraram, cozinharam, viajaram, se casaram, brigaram, se perdoaram, mas nunca se separam. Sendo uma sustentação da outra na questão do poder social.

É um casamento que realmente foi para sempre. Esta relação entre religião e política, é uma herança ainda do chamado descobrimento das terras brasileiras, e do domínio português por mais de 320 anos. Sendo Portugal um país europeu, e, estando sobre a direção de uma monarquia, estava estabelecido em bases da teoria teológico-políticas. Onde o poder pertence a Deus, ou seja, é teocrático. E, por meio da divindade vem aos seres humanos, sendo o rei o escolhido de Deus. A comunidade política se forma pelo pacto de submissão dos súditos ao rei (CHAUI, 2011).

Nessa estrada calçada por monarquia, religião e sociedade, é baseado a forma de fazer política na antiga terra de Vera Cruz. Porém, no ambiente da religião, se discursa sobre a divindade e os dogmas estabelecidos pela igreja católica. Nas questões políticas, o principal fundamento tem como proposta, apresentar um conceito de bem-estar para a sociedade. Porém, este modo de cuidado com o povo, parece não ter sido o principal objetivo dos governantes, nem na monarquia e tão pouco na república. Todavia, tratando sobre perspectivas políticas no Brasil, desde o fim do século XIX, com a instituição da república, as falas e discursos, encontram-se na maioria dos políticos brasileiros historicamente, a influência e importância da questão religiosa, pois de início são evocados a benção de Deus em suas campanhas e posteriormente repetindo-se esta prática em todos os locais dos poderes, seja no parlamento, nos palácios e nos tribunais.

RBPPD/BRJPD | Vol. 2 | n. 2 | 109-127, 2020. 
Na contemporaneidade este modo não mudou. São usadas citações bíblicas para agradecer ou falar de algum tema, o nome de Deus no início e/ou no fim de uma fala. Tais práticas puderam serem verificadas na sessão da câmara dos deputados que levou o afastamento da presidente Dilma em 2016. E os mesmos métodos nas campanhas ou divulgações de projetos ou trabalhos realizados durante o mandato. Com o uso de mensagens em vídeos, textos ou imagens, transmitidas em postagens nas redes sociais e nos aplicativos de mensagens. Meio este usado na campanha de 2018 em larga escala. Podemos apontar aqui, o uso de um novo recurso tecnológico de informação, porém para transmitir velhas mensagens.

Tratando sobre a inter-relação do estado e a religião, aprendemos tanto em uma análise mais apurada na perspectiva grega, no período da Antiguidade Clássica, quando não havia a ideia de um Estado de natureza prévio, mas de um estado prévio divino. Revelando que na teoria política antiga, já existia um fundamento de validade no sentido concreto de natureza divina como argumento $a$ priori, no sentido de existência mesmo sem verificação física (CHÂTELET; DUHAMEL; PISIERKOUCHNER, 2000 apud SABAINI, 2010). Realizar esta análise a partir do fenômeno religioso é fundamental para uma maior compreensão sociológica das questões políticas em todos os tempos. Segundo Mariano (2016) a religião sempre esteve no centro das investigações teóricas e históricas, onde os fundadores da Sociologia, como Durkheim e Weber, foram os que mais se dedicaram a investigar os fenômenos religiosos e seu impacto sociocultural e econômico.

Sendo os conceitos políticos do ocidente muito influenciados pelas ideais das pólis gregas, e posteriormente pela participação da Igreja Católica e após a reforma, existindo também uma contribuição das ideias protestantes. Os estados e as perspectivas políticas desde a monarquia estão sempre entrelaçados na vontade de Deus e nas decisões de uma corte ou soberano, e posteriormente nas ideias do povo. Mudando até as formas de se fazer a política. Podendo ser monárquica, parlamentarista, republicana, democrática, ditatorial, socialdemocrata, etc.

Mas em tese geral, os que fazem uso dos mecanismos religiosos para prática de promoção política, se apropriam do único texto que trata sobre essa temática no Novo Testamento: "Não exista autoridade que não proceda de Deus; e as autoridades que existem foram por eles instituídas" (BÍBLIA, ROMANOS, 13: 1). E, sendo o Brasil, um país colonizado por um estado europeu e fruto em sua história política da influência do religioso nas relações de poder, não poderia deixar de ter em seu histórico a influência da relação política e religião.

RBPPD/BRJPD | Vol. 2 | n. 2 | 109-127, 2020. 


\section{Os pentecostais e neopentecostais na política brasileira}

Baseando-se em versículo como: "Feliz a nação cujo Deus é o Senhor...” (Bíblia, Salmos, 33:12) e outros textos contidos no livro sagrado dos cristãos, porém não usando as devidas interpretações. Tem início um discurso religioso da obrigação da participação de cristãos na política partidária nos anos de 1980, nas denominações chamadas de Pentecostais e principalmente Neopentecostais, como a Universal do Reino de Deus. Este processo da militância política no meio Pentecostal e evangélico é marcado em um primeiro momento por disputas entre os pastores e membros que atuavam nas questões partidárias contra uma maioria de ministros religiosos e integrantes do quadro de filiados a Igreja, que eram extremante contrários a 'politica dentro da Igreja', pois esta era coisa do mundo (ARAUJO, 2007).

Rompendo todos estes desafios, os pentecostais avançam na construção de frentes políticas partidárias que envolviam o lançamento de candidaturas e até na organização e liderança de partidos. Com uma agenda conservadora e baseando-se em conceitos bíblicos e na maioria dos casos filiados a partidos considerados de direita ou de centro. Alinhados com membros de Igrejas tradicionais os representantes das Igrejas pentecostais e neopentecostais, ganham grande espaço dentro dos parlamentos estaduais e do congresso, e tornam-se também influentes junto aos poderes executivos na esfera municipal e estadual na maioria dos estados brasileiros. Havendo a formação de conselhos e órgãos para atuarem mais próximos da membresia sobre os assuntos políticos partidários dentro das próprias instituições religiosas ou em organizações que atuam em paralelo com as igrejas.

Nos governos de Fernando Henrique Cardoso, de 1994 a 2002, a relação entre a liderança evangélica pentecostal e a presidência da república sempre foi bem próxima, prova essa que o candidato apoiado por FHC, recebeu apoio da maioria de evangélicos pentecostais no segundo turno. Já que no primeiro turno, o maior apoio foi ao candidato Garotinho, que dizia se eleito, iria tomar posse com a Constituição Federal e com a Bíblia. Mas ainda, mesmo com a vitória do Partido dos Trabalhadores (PT) nos anos de 2002 e 2006 com Lula, e nos de 2010 e nas eleições de 2014 com Dilma. A relação entre pentecostais e neopentecostais não se distanciou do Palácio da Alvorada, sendo o partido comandado por membros da Universal, PRB (Partido Republicano

RBPPD/BRJPD | Vol. 2 | n. 2 | 109-127, 2020. 
Brasileiro) atual Republicanos, parte da base de apoio dos governos petistas e alguns parlamentares membros das denominações pentecostais e de outras igrejas neopentecostais também apoiavam os governos do PT. Existindo ainda, parlamentares petistas ou de partidos que faziam parte da coligação tanto em âmbito federal, como estadual, que foram apoiados por denominações evangélicas.

A bancada evangélica, contando principalmente com parlamentares das Igrejas Pentecostais, como das Assembleias de Deus e Neopentecostais, como a Universal. Avançam na ocupação de cadeiras no legislativo desde às eleições de 1994. Com exceção, a eleição de 2006, onde o número de parlamentares sofreu diminuição. Porém, nas eleições seguintes, o aumento foi exponencial. E a força política deste grupo, fez com que leis e projetos apresentados por partidos de esquerda ou de partido de centro, que possuíssem itens ou um viés ideológico contrário à suas crenças, fossem derrotados e pressionando até o governo a mudar ou retirar os respectivos projetos de pauta.

Desde a preparação e campanha eleitoral do ano 2010, onde haveria disputa para a presidência, governo dos estados e Distrito Federal, Senado, e para deputados estaduais/distritais e federais. Fortaleceu-se um projeto de atuação organizada e unificada por parte de deputados federais e lideranças evangélicas para superar os candidatos da esquerda. Sendo então iniciado em várias Igrejas e organizações religiosas. Cursos, seminários e congressos que explicavam sobre propostas de parlamentares, profissionais e líderes da esquerda brasileira que eram contrários aos costumes e práticas cristãs.

Fazendo uso do projeto da "Cartilha contra homofobia” chamado de 'Kit Gay' (CÂMARA FEDERAL, 2014) e o PL 122 (CÂMARA FEDERAL, 2006) tratada pelos parlamentares evangélicos como lei da mordaça ou ditadura gay. Estas propostas foram alvos de inúmeras ações dos parlamentares pentecostais e protestantes, e ainda serviu como plataforma política para que muitos candidatos e candidatas recebessem o voto dos evangélicos para serem eleitas nas eleições de 2010 e 2014. E ainda repercutiu nas eleições de 2018, sendo o candidato Fernando Haddad, atacado por adversários por na época ser o ministro da educação quando foi apresentado ao parlamento a discussão do projeto da cartilha contra a homofobia.

Ainda usando discursos com preceitos moralistas, com um projeto político onde a discussão do social e pautas sobre educação, saúde, ciência, sustentabilidade e outros temas são quase

RBPPD/BRJPD | Vol. 2 | n. 2 | 109-127, 2020. 
esquecidos e até inexistentes no histórico de parlamentares. É formada uma base religiosa política, que rompe o tempo que tratar de política na igreja era um pecado, para uma participação desprovida de conhecimento e práxis de políticas sociais voltadas para a população. Estabelecendo uma trincheira na defesa de seus valores e um exército que ataca os partidos que apoiam os projetos que se contrapõe aos costumes e doutrinas que os mesmos e suas instituições professam.

É nessa perspectiva, que deputados e senadores que foram chamados de fundamentalistas por representantes de partido de esquerda e centro. Organizam uma união, com parlamentares das áreas de segurança que foram eleitos com o discurso de alterar as leis do código penal e da constituição para endurecimento das penas, devido o aumento da violência nas grandes cidades e no campo. E representantes do agronegócio, que buscam ampliar sua participação na política brasileira com intuito de ajudar os projetos de grandes empresários do campo na expansão agroindustrial de corporações para plantio e criação de animais para abate no interior brasileiro.

Assim é formada a chamada frente BBB, bancada do Boi, da Bíblia e da Bala. Mas esses termos pejorativos e discursos contra as pautas defendidas por estes deputados, deputadas e senadores e senadoras, não diminuem a influência destes grupos, que unidos são a maior representação do congresso brasileiro. E estabelecendo uma relação de proximidade, aprovam suas agendas independente do governo.

Ao fim das eleições de 2014, o Brasil encontra-se dividido politicamente. Após inúmeros escândalos por parte integrantes do PT e partidos aliados e aumento expressivo dos conceitos da extrema-direita e participação efetiva de lideranças religiosas, ruralista, militares, organizações e grupos com base ideológica e interesses em políticas conservadoras. O governo petista reelege a candidata e então presidente Dilma Rousseff, mas tem uma bancada frágil e que está dependendo de vários partidos para ter maioria no congresso. Mas esta maioria apoia o deputado Eduardo Cunha para a presidência da Câmara Federal, e sendo o mesmo ligado a práticas não tão republicanas, o desfecho para uma crise institucional já poderia ser vislumbrado.

Sendo eleito a liderança da câmara, o então deputado Eduardo tem inúmeros conflitos com o governo e após receber vários pedidos de impeachment da presidente Dilma, este aceita um dos processos de impedimento em dezembro de 2015, e tem início um momento histórico, que fica conhecido para os militantes da esquerda e aliados, como golpe. Mas serve de base para um discurso antipetista, antipolítica e anticorrupção (o uso desse termo com interesses longe de seu

RBPPD/BRJPD | Vol. 2 | n. 2 | 109-127, 2020. 
significado), que é fortalecido pela imensidão de pessoas em passeatas, manifestações e em eventos, sendo o grande canal para estas divulgações, os vídeos editados e publicados na internet que tem condição de um alcance muito rápido de milhões de pessoas em poucos dias. E, já nas eleições municipais de 2016, temos os resultados que produzem o enfraquecimento enorme nas bases tanto de esquerda, centro e direita ligadas a políticos mais tradicionais e ainda derrotas fragorosas de candidatos destas agremiações para o executivo municipal, que são indicadoras dos resultados da eleição de 2018.

Após o processo do impeachment, o então vice-presidente, Michel Temer assume o país com um lema de ordem e progresso, tornando-se um presidente que já em sua posse, recebe oração e apoio de dezenas de líderes pentecostais, neopentecostais e de outras denominações evangélicas. No seu discurso e ações busca unir direita e centro. Mas é submetido a mesma politicagem de troca de cargos por apoio na câmara e senado e não consegue agradar a população. Além de acumular inúmeras denuncias de corrupção, tanto ligadas ao próprio presidente Temer como aos seus aliados. O governo caminha para o seu fim, e um vácuo existe em nomes mais conhecidos para a eleição presidencial do ano de 2018.

\section{A relação de Bolsonaro com pentecostais no processo da eleição de 2018}

O período de pré-campanha no ano de 2018 se inicia com uma dura polarização entre Lula, neste momento preso em Curitiba, e seu partido o PT, contra Bolsonaro, e seu partido o PSL. Havendo ainda outros candidatos que estão na luta de convencer a população a confiarem seu voto e assim chegarem no segundo turno, derrubando um dos dois candidatos que despontam como primeiro e segundo colocado em todas às pesquisas. Na prerrogativa de ser o maior partido de esquerda da América Latina, possuindo uma base de apoio estruturada e com nomes de políticos, intelectuais, artistas e empresários em consonância com seu projeto de governo.

O Partido dos Trabalhadores, mesmo enfrentando uma onda antipetista, não declina de lançar um nome para concorrer ao cargo mais alto da República, e assim articula para formar uma chapa competitiva e forte para essa eleição. Luiz Inácio, buscando ganhar tempo para organizar uma frente de apoio e convencer partidos de centro e esquerda a apoiarem o PT e nas entrelinhas, fornecerem apoio ao candidato que ele irá indicar para concorrer a presidência, mantém seu nome

RBPPD/BRJPD | Vol. 2 | n. 2 | 109-127, 2020. 
como candidato, pois a direção petista é ciente que devido decisões judiciais com base em lei da Ficha Limpa, o nome do ex-presidente não poderia ser candidato. Por isso, poucos dias antes de iniciar a corrida eleitoral, é lançado o nome de Fernando Haddad2, como candidato a presidente do Brasil pelo Partido dos Trabalhadores.

Todas estas circunstâncias e muitas questões relativas as redes sociais, aplicativos de mensagens, misturados com sentimentos de revolta e desesperança. Fazem nascer em meio a população o nome de um deputado que era considerado do baixo-clero da câmara federal. Mas que passa a ser conhecido na internet por seus discursos, que são marcados por uma mistura de Deus e força punitiva, família e fé, moral e ética, arma e Bíblia e muitas outras palavras e frases que o potencializaram a ser chamado de mito por seus correligionários. Este deputado que coloca seu nome para disputar a presidência, começa a receber apoio primeiramente dos membros das igrejas pentecostais e neopentecostais e outras denominações, é Jair Messias Bolsonaro3.

Este deputado é conhecido como controverso, populista e de extrema-direita. Conseguiu convencer os pentecostais a terem 'fé em mito' e acreditarem que pela força da espada é possível mudar. Extremamente diferente dos ensinos contidos no Novo testamento, e ainda fazendo ser esquecido a história da origem cristã. $\mathrm{O}$ então candidato recebe apoio expressivo nas redes sociais, de evangélicos, grupos de pessoas ligadas a segurança e ao agronegócio. E também de nomes conhecidos do empresariado brasileiro, artistas e políticos conservadores.

Bolsonaro tem uma candidatura marcada pela aproximação da bancada religiosa bem antes das eleições de 2018, assim como alguns membros das bancadas da segurança que também são militares e dos empresários do campo. Nos governos do PT e do MDB, o diálogo entre a bancada evangélica ocorreu em disputas ideológicas, sejam por comissões no congresso e por projetos que elevam os nomes dos representantes de cada grupo em suas bases. Por buscas por cargos e vantagens, sendo muito mais o apoio em alguns momentos por práticas fisiológicas.

2 Fernando Haddad, é advogado, mestre em Economia e doutor em Filosofia pela USP. Exerceu cargo na esfera pública e privada. Porém, seus cargos de maior destaque foram: Ministro da Educação (2005-2012), e prefeito de São Paulo (2013-2016).

3 Jair Messias Bolsonaro, é formado pela Academia das Agulhas Negras (AMAN) Capitão da reserva do exército, eleito pelo estado do Rio de Janeiro, estando em seu sexto mandato (2014-2018). Possuindo em seu currículo uma larga história de mudança partidária, não exercendo liderança de nenhum grupo na Câmara Federal, sendo do chamado baixo clero no parlamento. Lançou-se candidato a Presidência da República em 2018.

RBPPD/BRJPD | Vol. 2 | n. 2 | 109-127, 2020. 
Bolsonaro inicia sua campanha recebendo apoio de pastores do "segundo escalão assembleiano e de outras denominações" no início, e por obreiros e membros das Igrejas evangélicas em sua maioria e uma porcentagem considerável também da Igreja Católica. Havendo grande reverberação no início de sua campanha de apoio ao seu nome nas regiões centro-oeste, interior do sudeste e sul. Bolsonaro inicia uma cruzada que o faz agora ser ouvido com uma perspectiva que parece romper o congresso, Brasília e até a política brasileira, por pontuar entre os primeiros nas pesquisas e fazer com que todas às análises dos políticos, ex-presidentes, outros candidatos e cientistas políticos estivessem erradas ou pelo menos confusas.

Este discurso moralista que foi se construindo a cerca de oito anos atrás, com maior ímpeto nas Igrejas Pentecostais. Onde muitos nomes buscaram conquistar corações e votos, mas não alcançando êxito. Tem uma mudança no ano de 2018, sem um nome de consenso entre as lideranças pentecostais, mas com um nome conhecido por grande parte dos membros através das redes sociais e aplicativos de mensagens: Bolsonaro. Já decidido a ser candidato, Jair Bolsonaro realiza atividades de pré-campanha, passando por Igrejas, eventos religiosos, com apoiadores com mandato e sem mandato e aparecendo em fotos e vídeos que dizia está dando oportunidades para outros nomes na política para as candidaturas.

Ao definir seu slogan de campanha, une duas frases e assim constrói seu lema, combinação textual que agrada os eleitores cristãos, militares e os que defendem pensamento conservadores: "Brasil acima de tudo e Deus acima de todos". Lema este que tem origem com militares paraquedistas do exército brasileiro, na parte onde se diz: Brasil acima de tudo4, e segundo Bolsonaro, a segunda parte do slogan foi complementado em uma reunião evangélica, onde sendo convidado para fazer uso da palavra, ao terminar seu discurso ele repete a frase dos paraquedistas e completa: "e Deus acima de todos"5.

Desde o início da participação política mais efetiva de pastores e membros das Igrejas Pentecostais no início das décadas de 80 e 90, a distância da esquerda e aproximação da direita sempre foram práticas de maioria nos bastidores e palanques políticos organizado por religiosos. Como bem apresenta Machado (1998) falando da eleição de 1994, onde em uma pesquisa sobre a

4 Conforme noticiado pelo jornal Folha de São Paulo. Disponível em: < https://www1.folha.uol.com.br/poder/2018/10/slogan-de-bolsonaro-foi-inspirado-em-brado-de-paraquedistasmilitares.shtml > Acesso em 27. Jun. 2020.

5 Disponível em: < https://www.youtube.com/watch?v=gQT-vZP7qXg> Acesso em: 27. Jun. 2020.

RBPPD/BRJPD | Vol. 2 | n. 2 | 109-127, 2020. 
reprovação dos candidatos a presidência no meio evangélico, o então candidato Lula teve $45 \%$ de rejeição entre os Pentecostais. Esses dados já revelam como é desafiador para qualquer outro grupo, romper ou tratar sobre conceitos e práticas que estão enraizadas no meio pentecostal.

Havendo então na campanha de 1994, o mesmo discurso de questões ligadas a ideologia comunista, aos fatos sócio-políticos ocorridos no mundo naquele período e sobre as práticas do partido dos trabalhadores e seus aliados, que eram contrárias no entendimento dos líderes pentecostais, a liberdade religiosa e aos credos doutrinários cristãos. Confirmando assim, uma desconfiança dos Pentecostais com os candidatos petistas na história política brasileira. No ano de 2018 essa desconfiança permanece ou ressurge, conforme apresentou os dados de pesquisas do voto dos evangélicos em Bolsonaro, cerca de 70\% de apoio dos evangélicos (PESQUISA IBOPE, 2018). Deve-se perceber, que se em parte muita informação se passou a esse público, o conhecimento sobre a história política e a filosofia do constructo político em todas às esferas e perspectivas, é desconhecida por parte da população, e isso envolve os evangélicos brasileiros, apontando aqui os pentecostais como maioria.

Mesmo com o sistema comunista quase extinto no mundo, suas ideias e o histórico ditatorial de alguns governantes que se apresentavam como comunistas, ainda são úteis para serem usadas como plataformas de políticas de salvação do Brasil do comunismo. Sendo usado também como mote na campanha presidencial, do Brasil não se tornar uma Venezuela; isso por conta da crise econômica e política que enfrenta o país governado por um chavista. Bolsonaro se apropriando dessas perspectivas, realiza uma campanha, onde constroe uma narrativa baseada em um combate aos movimentos LGBTQI+, ao comunismo, ao ateísmo, promove cada vez mais um embate sobre a questão do "kit gay", traz uma mensagem sobre a valorização da família, amor a pátria e a fé em Deus.

Possuindo ainda na sua agenda, proposta do desarmamento, realizar ações contra o MST e MTST e outros grupos sociais como ONGS, sendo contra a demarcação de terras indígena, não apoiando os trabalhos de organizações não governamentais e grupos que desenvolvem ações sociais na área de educação que seguem perspectivas educacionais de Paulo Freire, contra o aborto e valorização da economia liberal.

Mas ainda nesse bojo, existem projetos que não contemplam direitos empregatícios, que não tem apoio aos trabalhadores e suas necessidades pessoais e familiares, mas apenas com o lucro

RBPPD/BRJPD | Vol. 2 | n. 2 | 109-127, 2020. 
da empresa contratante e muitas outras questões polêmicas. Porém, estas foram desconhecidas pelos eleitores, que ao considerarem às questões morais, não realizaram uma reflexão sobre os investimentos nas áreas do social, cultural e da previdência. Mesmo que a Frente Parlamentar Evangélica tenha entregue um projeto ou plano com diretrizes para novo governo no período da campanha de segundo turno para Bolsonaro, mas a prática dos parlamentares evangélicos sempre se baseou nos temas que tocam suas crenças e questões ligadas a moral.

Podemos então afirmar que o estado pode até ser laico, mas o voto é religioso. Pois baseados em discursos sobre Deus, o candidato derrotado do PT no fim do primeiro turno e no segundo turno, foi a missas, cultos e reuniões com pastores de ambos os lados, ganhou Bíblia, falou de familiares religiosos, tentou citar versículos, fez preces e ainda na companhia de sua esposa, e a candidata a vice-presidente e uma gama de correligionários, participou de vários eventos religiosos. Com tudo isso, a eleição de 2018 foi seguindo seu percurso da eleição que mais se evocou o nome de Deus nesses últimos vinte anos.

Bolsonaro também possui acesso muito amplo na Igreja Católica pentecostalizada, através dos movimentos carismáticos, que arrebatam milhões de pessoas desde grandes centros religiosos a pequenas salas de oração. Superando assim a força das CEBS e dos conceitos defendidos por teólogos da libertação. A participação de pentecostais supera o espaço evangélico, transcendendo ao católico também em participação e militância dos líderes. As comunidades carismáticas no catolicismo, tem trazido em seu discurso a renovação pelos dons do Espírito Santo segundo seus líderes. E estes atuaram como bastiões da campanha do então candidato do Partido Social Liberal - PSL.

Se Haddad teve distância de suas bases históricas, Bolsonaro ficou próximo dos pentecostais através do único caminho que eles entendem bem e que pode ser descrito em três palavras: Deus, Bíblia e família. Mesmo não apresentando propostas robustas e com qualidades de referências e planos de governo para as mais variadas áreas, ele conseguiu convencer a população no que o PT errou, ofuscando assim todas os projetos de apoio social e de desenvolvimento que o país também alcançou na gestão petista. E alavancou sua imagem de Messias, não se tratando aqui do seu sobrenome, mas no conceito das ideias e práticas populistas, que nada tem a ver com o modelo liberal que tanto foi divulgado por sua campanha.

RBPPD/BRJPD | Vol. 2 | n. 2 | 109-127, 2020. 
O candidato do PSL além de trazer nomes de pastores famosos no meio pentecostal para apoiá-lo, ainda contou com adesão um pouco antes do início da campanha e no segundo turno, de candidatos que vendo seu nome bem pontuado nas pesquisas, decidiriam manifestar publicamente o apoio a Bolsonaro. Esperando também surfar na onda da direita que banhou o Brasil. Mas alguns, assim mesmo, "morreram na praia". E com todo esse apoio, e ainda uma base organizada para envio de mensagens que desqualificavam os adversários, notícias falsas sobre planos de governo, fatos pessoais de outros candidatos e que mancharam imagens de pessoas públicas. Os resultados da eleição de 2018, deram a vitória a Jair Bolsonaro com cerca de 58 milhões de votos.

Bolsonaro falou de Deus e morte na campanha, juntou Jesus com torturadores, aplaudiu a ditadura e falou de liberdade, apresentou uma mensagem de pureza da honestidade acompanhado com nomes e vozes surjas da política nacional. Ainda sim, conseguiu não deixar ser percebida todas estas contradições pelo discurso religioso. Fazendo todos os partidos de esquerda e de centro reconhecerem a participação dos religiosos como fator preponderante para se vencer uma eleição.

E principalmente com o apoio dos pentecostais e neopentecostais. Salientamos ainda que o atual governo é construído e identificado a partir do seu slogan de campanha. Fazendo uma análise da primeira parte da frase que é Brasil acima de tudo, conseguimos perceber na parte teórica a presença deste afã nacionalista, carecendo de mais resultados para ser percebido na prática. Mas o Deus acima de todos, ainda não consegui contemplar em nenhum aspecto, pois somente onde existe amor, compreensão, verdade e paz, é que se revela que Deus estar acima de todos.

\section{Considerações Finais}

Concluimos este artigo, observando que Bolsonaro foi eleito presidente do Brasil em 2018 e tornou-se Messias dos políticos e eleitores pentecostais. Mesmo não sendo evangélico, desenvolveu a capacidade de se aproximar deste grupo social e dialogar com os mesmos a partir de um livro que os evangélicos consideram sagrado que é a Bíblia, fazendo citações de versículos e defendendo temas relacionados ao credos doutrinários cristãos, como ser contra o aborto, união homoafetiva, sacralidade da família, etc. Colaborando também para sua aproximação aos pentecostais, a relação com lideranças religiosas que apoiam seu nome para concorrer a presidência do Brasil.

RBPPD/BRJPD | Vol. 2 | n. 2 | 109-127, 2020. 
Apontamos que este trabalho colaborou em apresentar o campo pentecostal na sua frente política partidária e sua participação eleitoral para o cargo de presidente do Brasil na eleição de 2018. Trazendo novos olhares a partir de informações e análises de fatos que marcaram esse pleito eleitoral e fornecendo informações e perspectivas que instruem tanto o pesquisador assíduo desse campo de estudo seja sociológico, da Ciência da Religião ou de outra ciência. Como o leigo nessa temática, mas que se interessa nessas pesquisas ou tem o interesse político neste campo religiosopolítico.

Consideramos que a relação entre os líderes pentecostais e Bolsonaro ainda é um vasto campo de pesquisa. Temos ainda como inquietações e perguntas que pensamos poder servir como problemática para outros estudos e pesquisas. Apontamos algumas que são: como será o governo de Bolsonaro com uma base na maioria novata no Congresso e na estrutura dos ministérios e do governo? Quais os possíveis resultados desta forma de populismo dos trópicos? O povo brasileiro e principalmente os pentecostais, tem entendido e apoiado a atual postura do presidente? São interrogações que podem levantar novas hipóteses e cooperar com outros trabalhos, e assim buscarmos entender mais sobre a relação política e religião, tanto no contexto brasileiro e até mundial.

\section{Referências}

ALENCAR, Gedeon Freire. Matriz Pentecostal Brasileira: Assembleia de Deus 1911-2011. Rio de Janeiro: Novos Diálogos, 2013.

ARAUJO, Isael. Dicionário do Movimento Pentecostal. Rio de Janeiro: CPAD, 2007.

BÍBLIA, N. T. Romanos. In BÍBLIA. Português. Bíblia Sagrada: Antigo e Novo Testamentos. Tradução e versão de Almeida Revista e Corrigida. São Paulo: Sociedade Bíblica de Aparecida, 2008. p. 202-203.

RBPPD/BRJPD | Vol. 2 | n. 2 | 109-127, 2020. 
CÂMARA FEDERAL, 2011. Pressão de bancadas faz governo cancelar kit sobre homossexualidade. Fonte: Agência Câmara de Notícias. Disponível em:

<http://www2.camara.leg.br/camaranoticias/noticias/DIREITOSHUMANOS/197660-.html> Acesso em 04.dez.2018.

CHAUI, Marilena. Convite à Filosofia. São Paulo: Editora Ática, 2011.

COSTA, Luís César Amad e MELLO, Leonel Itaussu A. História do Brasil. São Paulo: Editora Scipone, 1999.

FERNANDO HADDAD. Disponível em: 〈https://pt.wikipedia.org/wiki/Fernando_Haddad〉 Acesso em: 13. jun. 2020.

MACHADO, Ziel J.O. Os Evangélicos e a Esquerda nas Eleições de 1994. Último Andar: caderno de pesquisa em ciências da religião/Programa de Estudos em Ciência da Religião, PUCSP. Ano 1, n.1. São Paulo: EDUC, 1998.

JAIR MESSIAS BOLSONARO. Disponível em: < https://pt.wikipedia.org/wiki/Jair_Bolsonaro> Acesso em: 13. Jun. 2020

MARIANO, Ricardo. Sociologia da Religião e seu foco na secularização. In: PASSOS, João Décio; USARSKI, Frank (ORGS.). Compêndio de Ciência da Religião. São Paulo: Paulinas: Paulus, 2016.

PESQUISA IBOPE, 2018. Disponível em: <https://noticias.uol.com.br/politica/eleicoes/2018/noticias/2018/10/16/bolsonaro-haddad-ricosevangelicos-regioes-ibope.htm>Acesso em 05.dez.2018.

SABAINI, Wallace Tesch. Estado e Religião: Uma análise à luz do direito fundamental à liberdade de religião no Brasil. São Paulo: Universidade Presbiteriana Mackenzie, 2010.

RBPPD/BRJPD | Vol. 2 | n. 2 | 109-127, 2020. 
CAMARA FEDERAL. Projeto de Lei da Câmara ${ }^{\circ}$ 122, de 2006, 2006 Altera a Lei n 7.716, de 5 de janeiro de 1989, que define os crimes resultantes de preconceito de raça ou de cor, dá nova redação ao $\S 3^{\circ}$ do art. 140 do Decreto-Lei n 2.848, de 7 de dezembro de 1940 - Código Penal, e ao art. $5^{\circ}$ da Consolidação das Leis do Trabalho, aprovada pelo Decreto-Lei ${ }^{\circ} 5.452$, de $1^{\circ}$ de maio de 1943, e dá outras providências. Disponível em:<https://www25.senado.leg.br/web/atividade/materias/-/materia/79604> Acesso em 04.dez.2018.

SEVERINO, Antônio Joaquim. Metodologia do Trabalho Científico. São Paulo: Cortez, 2015. 